\title{
Correction to: Fairness criteria for allocating scarce resources
}

\author{
Bismark Singh ${ }^{1}$ \\ Published online: 26 October 2020 \\ (c) Springer-Verlag GmbH Germany, part of Springer Nature 2020
}

\section{Correction to: Optimization Letters (2020) 14:1533-1541 https://doi.org/10.1007/s11590-020-01568-1}

The Acknowledgements section in the original publication of the article is now revised to the following.

Acknowledgements Open Access funding provided by Projekt DEAL. As suggested in Section 3, this work began with quadratic loss functions in the context of a resource allocation problem in vaccine allocation. Proportionally fair results for the special case of the quadratic loss appeared in the dissertation of Hsin-Chan (Neo) Huang [1] and in my dissertation [3], and were subsequently published by us in Huang et al. [2]. I sincerely thank Neo and David Morton for many helpful discussions that led to furthering that work, i.e., that led to the current paper. I further thank David for discussions on structuring this article. I also thank an anonymous reviewer for correcting an error in an earlier version of a proof. Anything overlooked in the manuscript is, of course, my responsibility.

\section{References}

1. Huang, H.C.: Stockpiling and resource allocation for influenza preparedness and manufacturing assembly. Ph.D. thesis, The University of Texas at Austin (2014)

2. Huang, H.C., Singh, B., Morton, D.P., Johnson, G.P., Clements, B., Meyers, L.A.: Equalizing access to pandemic influenza vaccines through optimal allocation to public health distribution points. PloS One 12(8), e0182720 (2017)

3. Singh, B.: Optimal spatiotemporal resource allocation in public health and renewable energy. Ph.D. thesis, The University of Texas at Austin (2016)

Publisher's Note Springer Nature remains neutral with regard to jurisdictional claims in published maps and institutional affiliations.

The original article can be found online at https://doi.org/10.1007/s11590-020-01568-1.

$\triangle$ Bismark Singh

bismark.singh@fau.de

1 Discrete Mathematics, Friedrich-Alexander-Universität Erlangen-Nürnberg, 91058 Erlangen, Germany 